\title{
Analysis of Chemical Compounds of Gaseous and Particulate Pollutants from the Open Burning of Agricultural HDPE Film Waste
}

\author{
Tae-Han Kim ${ }^{1}$, Boo-Hun $\mathrm{Choi}^{2}$, and Joongjin Kook ${ }^{3^{*}}$ \\ ${ }^{1}$ Professor, Department of Green Smart City, Sangmyung University, 31 Sangmyung-Daero, Dongnam-Gu, Cheonan-Si, Chungcheongnam- \\ Do 31066, Republic of Korea \\ ${ }^{2}$ Doctoral Student, Department of Environmental Resources, Sangmyung University, 31 Sangmyung-Daero, Dongnam-Gu, Cheonan- \\ Si, Chungcheongnam-Do 31066, Republic of Korea \\ ${ }^{3}$ Assistant Professor, Department of Information Security Engineering, Sangmyung University, 31 Sangmyungdae-gil, Dongnam-gu, Cheonan- \\ si, Chungcheongnam-do 31066, Republic of Korea
}

\section{ABSTRACT}

Background and objective: Illegal open-air incineration, which is criticized as a leading source of air pollutants among agricultural activities, currently requires constant effort and attention. Countries around the world have been undertaking studies on the emission of heavy metal substances in fine dust discharged during the incineration process. A precise analytical method is required to examine the harmful effects of particulate pollutants on the human body.

Methods: In order to simulate open-air incineration, the infrastructure needed for incineration tests complying with the United States Environmental Protection Agency (EPA) Method 5G was built, and a large-area analysis was conducted on particulate pollutants through automated scanning electron microscopy (SEM)-energy-dispersive X-ray spectroscopy (EDS). For the test specimen, high-density polyethylene (HDPE) waste collected by the DangJin Office located in Choongcheongnam-do was used. To increase the identifiability of the analyzed particles, the incineration experiment was conducted in an incinerator three times after dividing the film waste into $200 \mathrm{~g}$ specimens.

Results: Among the metal particulate matters detected in the HDPE waste incineration test, transition metals included $\mathrm{C}$ (20.8-37.1 wt\%) and O (33.7-37.9 wt\%). As for other chemical matters, the analysis showed that metal particulate matters such as metalloids, alkali metals, alkaline earth metals, and transition metals reacted to $\mathrm{C}$ and $\mathrm{C}-\mathrm{O}$. Si, a representative metalloid, was detected at 14.8-20.8 wt\%, showing the highest weight ratio except for $\mathrm{C}$ and $\mathrm{O}$.

Conclusion: In this study, the detection of metal chemicals in incinerated particulate matters was effectively confirmed through SEM-EDS. The results of this study verified that HDPE waste adsorbs metal chemicals originating from soil due to its own properties and deterioration, and that when incinerated, it emits particulate matters containing transition metals and other metals that contribute to the excessive production and reduction of reactive oxygen species.

Keywords: particulate matter (PM), mulching LDPE, agricultural waste burning, incineration test, back scattered electron (BES)

\section{Introduction}

According to the Clean Air Policy Support System (CAPSS), which is based on the Korean air pollutants emissions inventory, agriculture has the largest correction range among industries in which the emissions inventory is being aggregated. Continuous efforts are needed to prevent illegal open-air incineration, which is a representative source of air pollutants with respect to agricultural activities. Agricultural wastes subject to open-air incineration are ag-

This work was carried out with the support of "Cooperative Research Program For Agriculture Science and Technology Development (Project No.PJ014283022021)" Rural Development Administration, Republic of Korea.

Received: November 18, 2021, Revised: December 1, 2021, Accepted: December 9, 2021

First author: Tae-Han Kim, taehankim@smu.ac.kr, (1) https://orcid.org/0000-0001-8881-8429

*Corresponding author: Joongjin Kook, kook@smu.ac.kr, (1) https://orcid.org/0000-0002-0033-388X 
gregated by the Korea Environment Corporation (KECO) under the Ministry of Environment and reported as national approval statistics (approval number: 392005); the statistical results are announced on an annual basis as environmental statistics information in the Korea Resource Circulation Information System, and are further reported in the Agricultural Waste Survey publication in December of the year following the base year of the survey. The KECO has statistically counted any agricultural wastes that are collected by classifying them into the "amount of plastic waste generated from greenhouses," "amount of plastic waste from soil mulching," "amount of agricultural pesticide container waste" and "amount of collected/recycled agricultural plastic and pesticide container waste." With the exception of other categories of waste with relatively low emissions, it is possible to classify waste plastic from farming by type - i.e., low-density polyethylene (LDPE) for greenhouses, LDPE for soil mulching, and high-density polyethylene (HDPE).

The thermal decomposition of waste for the purposes of energy recovery is an effective method for reducing the volume and amount of plastic waste in landfills, but it causes air pollution by emitting harmful gaseous and particulate pollutants (Wang et al., 2003). The health effects of these emissions may be related to polycyclic aromatic hydrocarbons (PAHs), some of which have been identified to be potentially toxic, carcinogenic, or mutagenic (Amdur et al., 1993). PAHs are also analyzed as soot-forming precursors (Richter et al., 2006). Polyethylene (PE), a representative gummy plastic material, is the most widely used plastic, with an output of about 80 million tons worldwide (Merrington, 2017). Rice and Rice (1935) proposed a mechanism for the formation of free radicals through hydrogen extraction involved in the pyrolysis of PE. Simha et al. (1958) further explained the pyrolysis process of polymers through a general conceptual diagram. This mechanism includes several steps such as initiation, propagation or free-radical transfer, and termination. Interlocked with this mechanism, the primary pyrolysis of PE forms chains of various sizes with a very small number of monomer units (Williams and Williams, 1999). PE is mainly provided as LDPE and HDPE, depending on the polymerization method, of which physical properties such as den- sity, processability, flexibility, and strength vary (Andrady, 2011). With respect to the liquefaction properties (i.e., the amount of liquid generated) of LDPE, LLDPE, and HDPE, which are associated with the heating temperatures during pyrolysis, diesel was found to be the highest at $450^{\circ} \mathrm{C}$, followed by wax, kerosene, and gasoline (Yu et al., 2003). By examining the characteristics of the products recovered from HDPE pyrolysis, it was confirmed that the aliphatic of HDPE is easily decomposed into low-molecular gases (Lee et al., 2008).

Microplastics (MP), such as PE, can more effectively absorb metal ions through the degradation process when compared to unused plastics (e.g., virgin plastic pellets; Holmes et al., 2014). Based on an industrial analysis of plastics including polypropylene (PP), HDPE, and polystyrene (PS), the content of volatile matter was found to be $99.8 \%$ or more, but for plastic film waste, the content of volatile matter, fixed carbon, and ash was $80.8 \%, 11.6 \%$, and $6.3 \%$, respectively, which showed a relatively lower amount of volatile matter, and a higher amount of fixed carbon and ash when compared to the plastics. The reason why plastic film waste has relatively higher amounts of fixed carbon and oxygen than the plastics used as a control is that it includes plastic films manufactured using polymers containing oxygen as raw materials (PET or bioplastics), as well as those made of thermoplastic resins (PP, HDPE, and PS; Kim et al., 2017). PE also contributes to significant changes in $\mathrm{CO}$ emissions when incinerated together with agricultural byproducts. Hosseini et al. (2014) reported that when a mixed specimen of manzanita (Arctostaphylos sp.), which is native to North America, and LDPE was incinerated, the CO emission factor was different depending on the LDPE content, but also that the PE had an effect on the increase in combustion efficiency, so further statistical review would be needed.

Countries around the world have been conducting research on the components of emissions from various incineration processes, and it has been reported that the smaller the particle size, the greater the concentration of heavy metals (Wadge and Hutton, 1987; Wei et al., 2021). A precision analysis method is required to examine particulate pollutants that are harmful to the human body. Energy dispersive X-ray spectroscopy (EDS) is a non-destructive 
Table 1. Amount of agricultural plastic waste generated and collected in 2018 (Korea Environment Corporation, 2019)

\begin{tabular}{ccccc}
\hline & $\begin{array}{c}\text { Total waste generation } \\
\text { (ton) }\end{array}$ & $\begin{array}{c}\text { Total waste collection } \\
\text { (ton) }\end{array}$ & $\begin{array}{c}\text { Amount of plastic not collected } \\
\text { (ton) }\end{array}$ & $\begin{array}{c}\text { Uncollected rate } \\
\text { (\%) }\end{array}$ \\
\hline Greenhouse LDPE & 68,758 & 5,420 & 63,338 & 92.1 \\
Mulching LDPE & 127,431 & 96,564 & 30,867 & 24.2 \\
HDPE & 112,909 & 96,847 & 16,062 & 14.2 \\
Etc. (PVC, EVA, PO) & 9,677 & 1,588 & 8,089 & 83.6 \\
\hline Sum & 318,775 & 200,419 & 118,356 & 37.1 \\
\hline
\end{tabular}

method that does not require extraction or decomposition processes, enabling us to analyze particulate matter in elemental units.

In this study, we established an incineration experiment infrastructure where the United States Environmental Protection Agency (US EPA) Method 5G was applied for open-air incineration simulation. We also conducted a time series analysis of gaseous pollutants such as $\mathrm{CO}$, and an analysis of particulate pollutants in elemental units, all of which were emitted from the open-air incineration of agricultural HDPE waste. The purpose of this study was to determine the effect of emissions from the open-air incineration of agricultural plastic wastes on carbon neutrality and to provide basic data on the emission characteristics of metal particulate matter (PM).

\section{Research Methods}

\section{Open-Air Incineration of Agricultural Plastic Waste}

For the open-air incineration of agricultural plastic waste, the emission of particulate and gaseous pollutants is estimated by applying the agricultural population (households), the amount of waste incinerated per capita, the open-air incineration rate, and the emission factor; improvement in the activity data based on the relevant statistical data is required. First of all, the amount of waste incinerated per person and the open-air incineration rate of agricultural plastic waste are broken down into Greenhouse HDPE, Mulching LDPE, and HDPE based on findings from the Statistical Survey on Agricultural Waste 2019 (Korea Environment Corporation, 2020), which are
KECO's standard agricultural waste statistics (Table 1). For statistical data that can be used to determine activity levels, the current status of agricultural byproduct and waste incineration in rural areas can be obtained from $A$ Survey on the Incineration of Agricultural By-products and Wastes in Rural Areas (Ministry of Agriculture Food and Rural Affairs, 2020), in which the classification system of MAFRA, the competent authority, is used. For agricultural populations, nationally approved statistical data from KOSIS (2019) can be used; for the status of agricultural waste incineration, the survey described above can apply. Of the 536 farmers who responded to the survey, 3 have burned greenhouse plastic film and 76 have burned various types of plastic waste.

\section{Sample Design}

Agricultural waste is a byproduct generated when materials used to grow crops are disposed, and this can refer to various plastics including pesticide bags, fertilizer bags, shading screens, non-woven fabrics, fruit bags, and greenhouse plastic film, as well as supports and pedestals. Along with the use of various agricultural materials, agricultural activities generate a large amount of plastic byproducts, which can be defined as agricultural plastic waste. According to KECO (2020), a total of 310,153 tons of agricultural plastic waste was generated in 2019. In terms of the type of plastic, the use of LDPE for soil mulching was the highest at 129,253 tons, followed by HDPE (106,298 tons), LDPE for greenhouses (59,133 tons), and others (15,468 tons). In this study, among the wastes listed here, HDPE was selected as a specimen for the incineration experiment. The specimens, which were $20 \mathrm{~kg}$, were provided by the DangJin Office of the KECO. 


\section{Experimental Setup Design}

For the real-time monitoring of gaseous pollutants emitted during the incineration of agricultural HDPE waste, an experimental infrastructure based on the EPA Method 5G was established (Fig. 1). It has a structure in which particulate and gaseous pollutants emitted from HDPE that burn in the incinerator are forcibly exhausted towards a blower, which is equipped at the end of the passage. In addition to the time-series measurement of $\mathrm{CO}$ generated from the combustion of HDPE, PM including soot, tar, and unburned oligomers were captured by installing a filter (HG00047A, $\varnothing 47 \mathrm{~mm}$ ) in the filter box (Hosseini et al., 2014). For the time-series monitoring of gaseous pollutants, an analyzer box (Testo 350K, Germany) was connected to the infrastructure, and the wind speed was measured in a time series using a Pitot tube (Testo, 0635 2145, Germany). Three sessions of the incineration experiment were performed in an incinerator after dividing the specimens into $200 \mathrm{~g}$ for each session. The collected emissions data on gaseous pollutants were statistically processed and a time-series analysis was performed.

Further, the specimens in which particulate contaminants were captured were pretreated with an ion sputter coater
(G20, GSEM, Korea), and carbon compound particles were examined for each specimen through a scanning electron microscope (SEM, CUBE III, Emcrafts) equipped with EDS (QUANTAX-610X, Bruker). X-ray spectra were set at a $20 \mathrm{kV}$ accelerating voltage under the control of software (Esprit Compact, Bruker), and the working distance (WD) was set to 11-13. The average weight ratio of the elements, which were repeatedly detected for 300 seconds for each specimen, was calculated. The weight ratio was repeatedly analyzed three times for each detected PM.

\section{Results and Discussion}

\section{Experimental Setup Analysis}

The setup for the incineration experiment was analyzed following the classification of incineration time, incineration weight, average airflow rate, number of PM, and average gas temperature (Table 2). The incineration time was counted differently depending on the specimen used, as the difference in soil or absorbed matter on the specimen surface is considered to affect the time at which combustion was completed. The actual incineration weight of the speci-

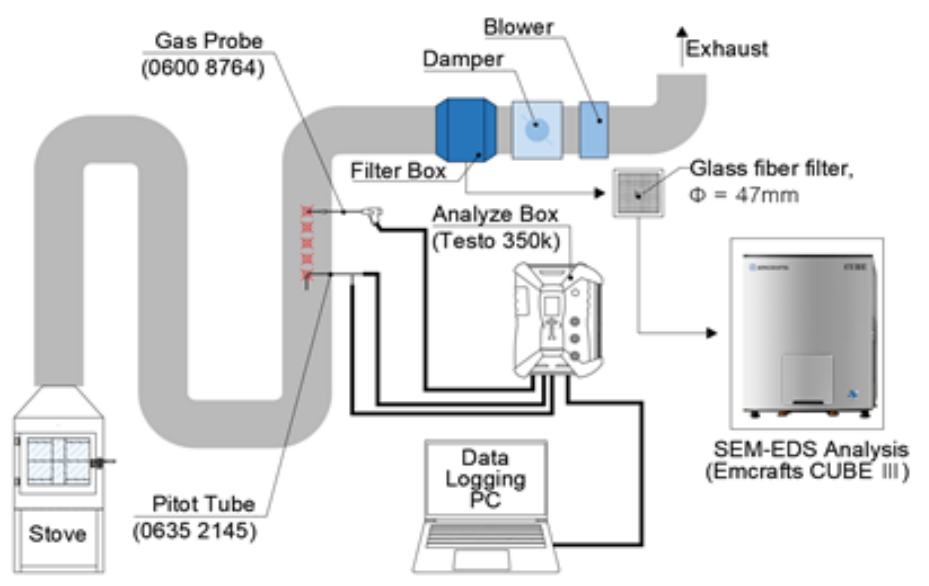

Fig. 1. Diagram of the test infra for the incineration experiment of HDPE waste.

Table 2. Conditions for the incineration experiment of HDPE film waste collected in DangJin

\begin{tabular}{ccccc}
\hline Repeat & Time $(\mathrm{min})$ & Weight $(\mathrm{g})$ & Avg. Airflow $\left(\mathrm{m}^{3} / \mathrm{min}\right)$ & Avg. gas temperature $\left({ }^{\circ} \mathrm{C}\right)$ \\
\hline 1st & 13.27 & 126.60 & 0.09 & 73.23 \\
2nd & 7.43 & 72.50 & 0.14 & 65.10 \\
3rd & 13.30 & 138.00 & 0.20 & 70.30 \\
\hline
\end{tabular}




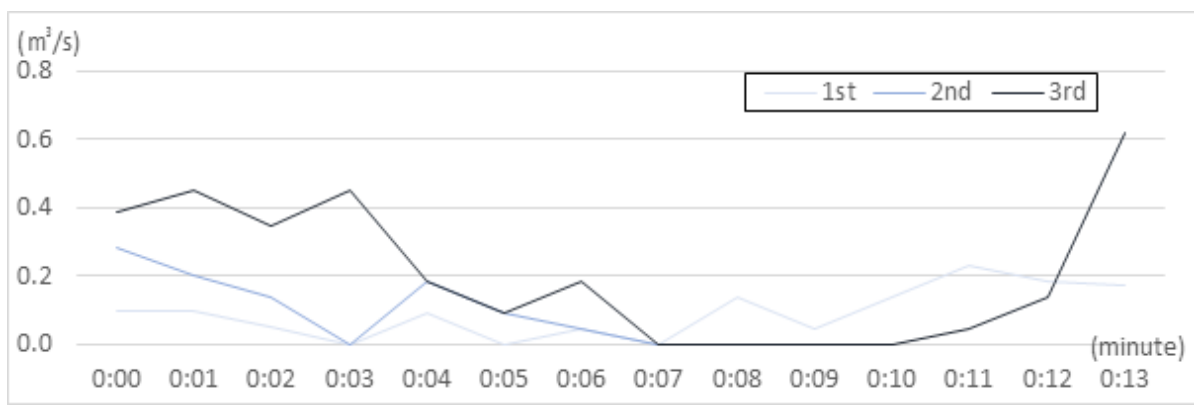

Fig. 2. Time-series monitoring of the airflow rate from the incineration experiment of the HDPE film waste.

Table 3. Results of air-flow rate monitoring from the incineration experiment of HDPE film waste (unit : $\mathrm{m}^{3} / \mathrm{min}$ )

\begin{tabular}{cccc}
\hline & $1^{\text {st }}$ & $2^{\text {nd }}$ & $3^{\text {rd }}$ \\
\hline Mean & 0.09 & 0.14 & 0.20 \\
Max & 1.59 & 1.59 & 1.59 \\
Min & 0.00 & 0.00 & 0.00
\end{tabular}

mens that underwent the incineration experiment ranged from $87.0-112.3 \mathrm{~g}$, which indicates that the specimens underwent significant incineration. For the average airflow rate, the blower applied to the experimental infrastructure was set at the minimum operating range (input/power consumption: $260 \mathrm{~W} / 432 \mathrm{~W}$, maximum static pressure: $34 \mathrm{mmAq}$ ) to maintain consistent operating conditions for each session of the experiment. The temperature at which the gas was captured in the gas probe for gaseous pollutants was in an incineration range of $65.10^{\circ} \mathrm{C}-73.23^{\circ} \mathrm{C}$, indicating that temperatures below $100^{\circ} \mathrm{C}$ were counted.

\section{Incineration Analysis}

The airflow rate generated during incineration of agricultural HDPE waste is shown in Fig 2. and Table 3. It was measured that the combustion airflow rate started at 0.1-0.4 $\mathrm{m}^{3} / \mathrm{min}$ at the beginning and decreased rapidly between $3-5$ minutes after combustion. The average airflow rate for each session ranged from $0.09-0.20 \mathrm{~m}^{3} / \mathrm{min}$, which is considered to be caused by atypical factors related to the specimens, such as materials adsorbed on the surface, plastic density, and variations in thickness, even in the same HDPE film waste.

\section{CO Analysis}

There are many existing research results on organic compounds generated during incineration and pyrolysis of plastic waste. Based on studies that examined the concentration of volatile organic compounds emitted in the process of pyrolysis through incineration experiments on PETE, HDPE, PVC, LDPE, PP, PS, and so forth, it was found that the concentration of aliphatic alkene compounds, including 1-hexenes, 2-hexene, 1-pentene, 2-pentene, 2-butene, and cyclopentane was $74.8 \%$, as identified during the incineration test of HDPE waste, and that of furan-based compounds was also high, whereas chlorine-based compounds were not detected (Lee and Kim, 2004). During an incineration experiment of wood flour-HDPE composites, when the amount of $\mathrm{CO}$ generated during the incineration process was measured, the $\mathrm{CO}$ emission increased up to $900 \mathrm{ppm}$ over time after about 600 seconds following the start of the incineration process. In this instance, and for those composites that contained magnesium hydroxide (MDH), which is an inorganic flame retardant, a relatively small amount of $\mathrm{CO}$ emission of about 300 ppm was measured (Shin et al., 2012).

The concentration of $\mathrm{CO}$ generated during the incineration of agricultural HDPE waste is shown in Fig. 3 and Table 4. During all sessions, the CO concentration in- 


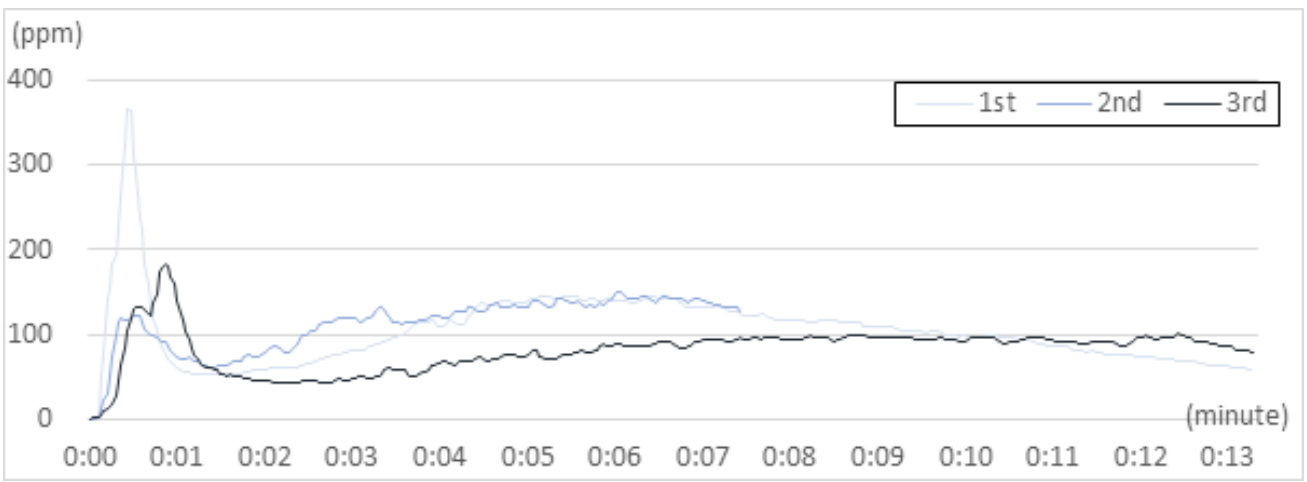

Fig. 3. Time series monitoring of $\mathrm{CO}$ emissions from the incineration experiment of HDPE film waste.

Table 4. CO monitoring results from the incineration experiment of HDPE film waste

(unit: ppm)

\begin{tabular}{cccc}
\hline & $1^{\text {st }}$ & $2^{\text {nd }}$ & $3^{\text {rd }}$ \\
\hline Mean & 104.26 & 112.58 & 81.27 \\
Max & 366.00 & 151.00 & 182.00 \\
Min & 0.00 & 0.00 & 2.00 \\
\hline
\end{tabular}

Table 5. Chemical element analysis of carbon compound particles from the incineration experiment of HDPE film waste

(unit: wt\%)

\begin{tabular}{|c|c|c|c|}
\hline Chemical element & Sample 1 & Sample 2 & Sample 3 \\
\hline $\mathrm{C}$ & $32.7 \pm 2.3$ & $37.1 \pm 2.2$ & $20.8 \pm 1.1$ \\
\hline $\mathrm{O}$ & $33.8 \pm 0.5$ & $33.7 \pm 0.9$ & $37.9 \pm 1.4$ \\
\hline $\mathrm{F}$ & $0.4 \pm 0.6$ & ND & ND \\
\hline $\mathrm{Na}$ & $3.4 \pm 0.3$ & $2.9 \pm 0.2$ & $4.7 \pm 0.5$ \\
\hline $\mathrm{Al}$ & $2.1 \pm 0.1$ & $1.8 \pm 0.2$ & $2.6 \pm 0.1$ \\
\hline $\mathrm{Si}$ & $16.9 \pm 1.1$ & $14.8 \pm 0.5$ & $20.8 \pm 1.1$ \\
\hline $\mathrm{K}$ & $2.4 \pm 0.2$ & $2.3 \pm 0.2$ & $2.9 \pm 0.2$ \\
\hline $\mathrm{Ca}$ & $1.2 \pm 0.1$ & $1.1 \pm 0.0$ & $1.4 \pm 0.1$ \\
\hline $\mathrm{Ti}$ & $0.4 \pm 0.5$ & ND & ND \\
\hline $\mathrm{Zn}$ & $3.0 \pm 0.4$ & $2.5 \pm 0.3$ & $3.7 \pm 0.3$ \\
\hline $\mathrm{Ba}$ & $3.9 \pm 0.5$ & $3.7 \pm 0.2$ & $5.2 \pm 0.4$ \\
\hline
\end{tabular}

creased rapidly from the beginning of combustion and reached a maximum concentration between 0 and 1 minute after the beginning. This concentration rapidly decreased immediately after reaching the maximum concentration, and then it tended to converge at $100 \mathrm{ppm}$, which was maintained until the end of combustion. The average $\mathrm{CO}$ concentration for each session was measured to be $81.27-$ $112.58 \mathrm{ppm}$, and the maximum concentration was recorded as $122.58 \mathrm{ppm}$ in the $2 \mathrm{nd}$ session.

\section{Carbon Compound Particle Analysis}

The SEM-EDS analysis was used to identify the chemical composition of the specimens by analyzing the element distribution of PMs with an even carbon content among the particulate pollutants detected for each specimen (Table 5). Among the PMs, C (20.8-37.1 wt\%) and O (33.7-37.9 wt $\%$ ) were detected at constant levels during the incineration of agricultural HDPE waste specimens. For the other chemical compounds, it was analyzed that metal PMs 

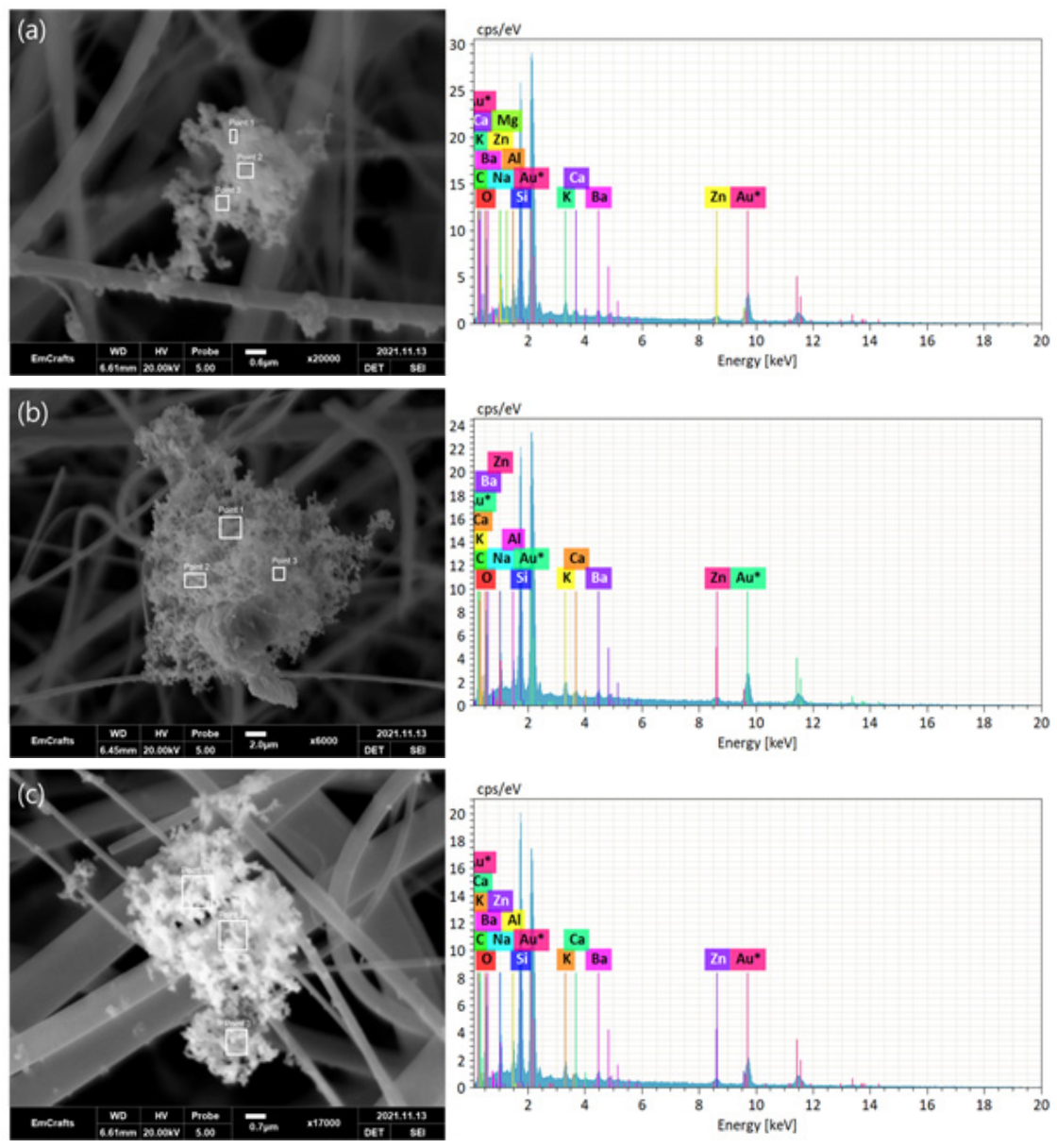

Fig. 4. SEM-EDS elemental analysis of particles from incineration experiment of HDPE film waste collected in DangJin. (a) Sample 1, (b) Sample 2, (c) Sample 3.

including metalloids, alkali metals, alkaline earth metals, transition metals, and other metals reacted with $\mathrm{C}$ and $\mathrm{C}-\mathrm{O}$. As a representative metalloid, 14.8-20.8 wt\% of $\mathrm{Si}$ was detected, which was deemed to have the highest weight ratio, excluding $\mathrm{C}$ and $\mathrm{O}$. In addition, the metals that showed a high reaction with $\mathrm{C}$ and $\mathrm{C}-\mathrm{O}$ among the captured PMs were alkaline earth metals including $\mathrm{Ba}(2.7-5.2 \mathrm{wt} \%)$ and $\mathrm{Ca}(1.1-1.4 \mathrm{wt} \%)$, as well as alkali metals including $\mathrm{Na}(2.9-4.7 \mathrm{wt} \%)$ and $\mathrm{K}(2.3-2.9 \mathrm{wt} \%)$. On the other hand, for transition metals capable of generating reactive oxygen species (ROS) in living organisms, $\mathrm{Zn}$ and $\mathrm{Ti}$ were detected. As small amounts of Ti were detected (0.4 wt $\%$, $\mathrm{SD}=0.5)$ in Sample 1 alone, it was not regarded as a major chemical compound, while $\mathrm{Zn}$ was found to have an even weight ratio of $2.5^{-3.7} \mathrm{wt} \%$ across all PMs. The other metal, Al, was also measured to have a significant weight ratio of $1.8-2.6 \mathrm{wt} \%$.
Therefore, for PMs with an even amount of $\mathrm{C}$ and $\mathrm{O}$ content, metalloids, alkali metals, and alkaline earth metals were analyzed to have a relatively high weight ratio compared to transition metals and other metals. The characteristics of these elemental units can be confirmed through the micrographs of PMs presented in Fig. 4. PMs that reacted with various metals maintained a shape like an aggregate of small particles, which was similar to the aggregate of minerals analyzed using SEM in a previous study (Slezakova et al., 2008). These shapes tended to be found in all analyzed PMs.

Transition metals such as $\mathrm{Zn}$, which were counted at a relatively low weight ratio in the samples, but were detected at constant levels in all samples, can generate ROS in living organisms. ROS are involved in the complex balance of control mechanisms that contribute to cell survival or death through intracellular signal transduction and chem- 
ical communication between cells (Habtemariam, 2019). Transition metals such as $\mathrm{Fe}, \mathrm{Cu}, \mathrm{Ni}$, and $\mathrm{Cr}$ also affect oxidative stress (OS) on biological tissues. OS can be developed by diminished antioxidant defenses, via redox cycling caused by semiquinone radicals of ROS generated by organic compounds adsorbed to particles, and through activated macrophages (Karlsson et al., 2005).

\section{Conclusion}

In this study, an incineration experiment infrastructure was established based on the EPA Method 5G for open-air incineration simulation, and $20 \mathrm{~kg}$ of the specimens used for the incineration experiment were provided by the DangJin Office of the KECO. A time-series analysis of $\mathrm{CO}$ gaseous pollutants and an analysis of particulate pollutants in elemental units were performed, which were emitted during the open-air incineration of agricultural HDPE waste specimens. The experimental setup for the incineration test was reviewed by classifying its properties into incineration time, incineration weight, average airflow rate, number of particles, and average incineration gas temperature. Further, airflow analysis, $\mathrm{CO}$ analysis, and carbon compound analysis were performed. For particulate contaminants, the captured samples were pre-treated with an ion sputter coater, and carbon compound particles were examined for each sample through SEM-EDS. The SEM-EDS analysis was used to determine the chemical composition by analyzing the elemental distribution of PM with an even carbon content among the captured particulate pollutants. The PM was detected at constant levels of $\mathrm{C}$ and $\mathrm{O}$ generated during the incineration of agricultural HDPE waste samples. For the other chemical compounds, metal PMs were analyzed for their reactions with $\mathrm{C}$ and C-O, including metalloids, alkali metals, alkaline earth metals, transition metals, and other metals.

The limitation of this study was that the HDPE waste used was limited to samples collected from a single region, and analysis of particles smaller than $1 \mu \mathrm{m}$ was not performed due to the limitations of SEM-EDS analysis capabilities. In addition, the general chemical composition derived through a qualitative analysis was not presented, as the results focused on the findings from a quantitative analysis. In the future, the findings from this work should be supplemented through follow-up studies. Additional research should be conducted to carry out an in-depth analysis of whether particulate pollutants containing metal compounds emitted from the incineration of HDPE are harmful to the human body.

\section{References}

Amdur, M.O., J. Doull, and C.D. Klaassen. 1993. Casarett and doull's Toxicology: The basic science of poisons, 4th edition. J. Occup. Environ. Med. 35(1):76.

Andrady, A.L. 2011. Microplastics in the marine environment. Mar. Pollut. Bull. 62(8):1596-1605. https://doi.org/10. 1016/j.marpolbul.2011.05.030

Habtemariam, S. 2019. Modulation of reactive oxygen species in health and disease. Antioxidants. 8(11):513. https:// doi.org/10.3390/ antiox8110513

Holmes, L.A., A. Turner, and R.C. Thompson. 2014. Interactions between trace metals and plastic production pellets under estuarine conditions. Mar. Chem. 167(20):25-32. https:// doi.org/10.1016/j.marchem.2014.06.001

Hosseini, S., Shrivastava, M, L. Qi, D.R. Weise, D.R. Cocker, J.W. Miller, and H.S. Jung. 2014. Effect of lowdensity polyethylene on smoke emissions from burning of simulated debris piles. J. Air Waste Manag. Assoc. 64(6): 690-703. https://doi.org/10.1080/10962247.2014.882282

Karlsson, H.L., L. Nilsson, and L. Moller. 2005. Subway particles are more genotoxic than street particles and induce oxidative stress in cultured human lung cells. Chem. Res. Toxicol. 18(1):19-23. https://doi.org/10.1021/tx049723c

Kim, Y.M., B.R. Lee, T.W. Han, S.D. Kim, T.U. Yu, B.Y. Bang, J.S. Kim, and Y.K. Park. 2017. Research on pyrolysis properties of waste plastic films. Appl. Chem. Eng. 28(1):23-28. https://doi.org/10.14478/ace.2016.1091

Korea Environment Corporation. 2020. Survey on the agricultural wastes in the 2019. Incheon, Korea. Retrieved from http://www.kwaste.or.kr/bbs/board.php?bo_table=board $17 \& w r$ id $=138$

KOSIS. 2020. Agriculture, Forestry and Fisheries Survey. Daejeon, Korea. Retrieved from http://meta.narastat.kr/ metasvc/svc/SvcMetaDcDtaPopup.do?orgId=101\&confmNo 


$$
=101045 \& \text { kosis } Y n=Y
$$

Lee, B.K. and H.A. Kim. 2004. Analysis of VOCs produced from incineration of plastic wastes using a small-electric furnace. J. Korean Soci. Atmos. Enviro. 20(6):759-771.

Lee, D.H., H.J. Choi, D.S. Kim, and B.H. Lee. 2008. Distribution characteristics of pyrolysis products of polyethylene. Polymer 32(2):157-162.

Merrington, A. 2017, 9 - Recycling of plastics. In applied plastics engineering handbook (Second Edition); Kutz, M., Ed.; William Andrew, Inc. (pp.167-189).

Ministry of Agriculture, Food and Rural Affairs. 2020. Survey on the incineration of agricultural byproducts and wastes in rural areas. Sejong, Korea: Kim, H.S. Retrieved from https://librarian.nl.go.kr/LI/contents/L20101000000.do? viewKey $=706798636 \&$ viewType $=$ AH $1 \&$ typeName $=$ $\% \mathrm{EC} \% 9 \mathrm{D} \% \mathrm{BC} \% \mathrm{~EB} \% \mathrm{~B} 0 \% 98 \% \mathrm{~EB} \% 8 \mathrm{~F} \% 84 \% \mathrm{EC} \% 84$ $\% 9 \mathrm{C}$

Rice, F.O. and K.K. Rice. 1935. The aliphatic free radicals. Retrieved from https://www.nature.com/articles/136415b0

Richter, H., J.B. Howard, and J.B. Vander Sande. 2006. Industrial production of fullerenic materials. Prepr.Pap. -Am.Chem.Soc., Div. Fuel Chem. 51(1):92.

Shin, B.W., Y.H. Song, J.H. Lee, D.S. Bang, and K.S. Chung. 2012. Smoke characteristics of wood flour-high density polyethylene composites. J. KOSHAM. 12:141-146.

Simha, R., L.A. Wall and J. Bram. 1958. High-speed computations in the kinetics of free-radical degradation. i. random initiation. J. Chem. Phys. 29:894-904. https://doi.org/10.1063/1.1744608

Slezakova, K., J.C.M. Pires, M.C. Pereira, F.G. Martins, and M.C. Alvim-Ferraz. 2008. Influence of traffic emissions on the composition of atmospheric particles of different sizes-Part 2: SEM-EDS characterization. J. Atmos. Chem. 60(3):221-236. https://doi.org/10.1007/s10874-008-9117-y

Wadge, A. and M. Hutton. 1987. The cadmium and lead content of suspended particulate matter emitted from a U.K. refuse incinerator. Sci. Total Environ. 67(1):91-95. https://doi.org/10.1016/0048-9697(87)90068-4

Wang, Z., J. Wang, H. Richter, J.B. Howard, J. Carlson, Y.A. Levendis. 2003. Comparative study on polycyclic aromatic hydrocarbons, light hydrocarbons, carbon monoxide, and particulate emissions from the combustion of polyethylene, polystyrene, and poly (vinyl chloride). Energy Fuels 17(4):999-1013, https://doi.org/10. 1021/ef020269z

Wei, Y., G. Liu, B. Fu, Y. Liu, and X. Xue. 2021. The transformation and enrichment of $\mathrm{Cd}$ in fine particulate matter during coal combustion: The key roles of Ti-bearing components. Fuel 292(15):120285. https://doi.org/10.1016/ j.fuel.2021.120285

Williams, P.T. and E.A. Williams. 1999.Interaction of plastics in mixed-plastics pyrolysis. Energy Fuels. 13:188196 https://doi.org/10.1021/ef980163x

Yu, H.J., B.H. Lee, and D.S. Kim. 2003. Liquefaction characteristics of HDPE by pyrolysis. Polymer 27(1): 84-89. 